\title{
DEVELOPMENT AND OPTIMIZATION OF HEAT TRANSFER PERFORMANCE ON THERMAL CONDUCTIVITY USING NANOFLUID
}

\author{
BIJAYALAKSHMI DAS ${ }^{1}$, PAVAN KUMAR M V ${ }^{2}$, SRIHARSHA SRIPATHI ${ }^{3}$ \\ ${ }_{1,2 \& 3}{ }^{A}$ ssistant Professor, Dept of Mechanical Engineering, Ramaiah Institute of Technology, Bangalore, India
}

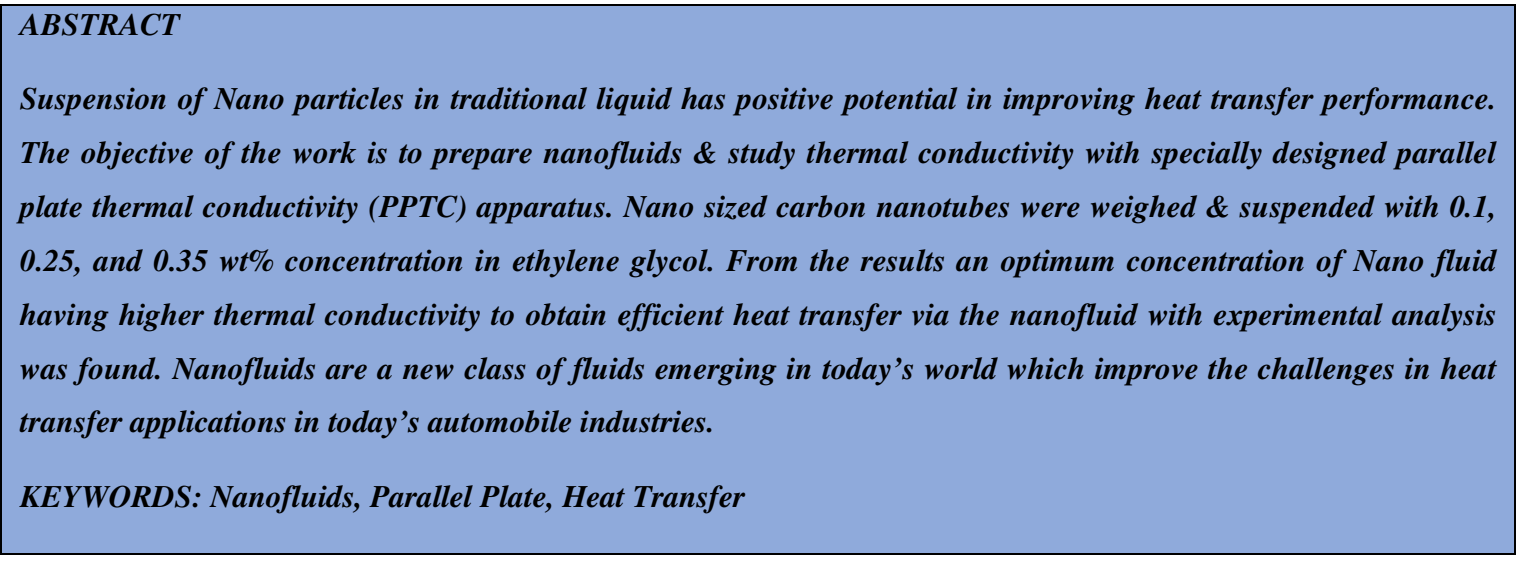

Received: Jun 08, 2020; Accepted: Jun 28, 2020; Published: Sep 16, 2020; Paper Id.: IJMPERDJUN20201271

\section{INTRODUCTION}

The traditional heat exchange fluids, for example water, ethylene glycol, and thermic liquids, are generally utilized in different modern applications including refrigeration and cooling, transportation, solar power based thermal and microelectronics. As the years cruise by, advancement of thermal system assumes an essential job in vitality utilization since vitality prices have been taking off quickly. Notifying that the regular thermal liquid has low thermal conductance, researchers make accessible of various designing techniques on the cooling system in improving heat transfer.

Nanofluid is termed as Nano meter sized particles dispersed in base fluids such as silicone oil, ethylene glycol, water, oil, etc. Nanofluids have great advantage over conventional heat transfer fluids. A very little quantity of nanoparticles when uniformly scattered in base fluids can provide drastic change in thermal properties of fluids. Nano particles have shapes such as spheres, disks, rods, tubes etc. These particles have higher surface area which carries more amount of heat than milli and micro sized particles.

\section{Thermal Conductivity of Nanofluids}

Thermal conductivity is the proportion of the capacity of Nanofluids to exchange heat. The thermal conductivity is the thermal energy exchanged per unit time and per unit surface region, partitioned by the temperature contrast. Fig. 1 indicates the factors affecting thermal conductivity of nanofluids 


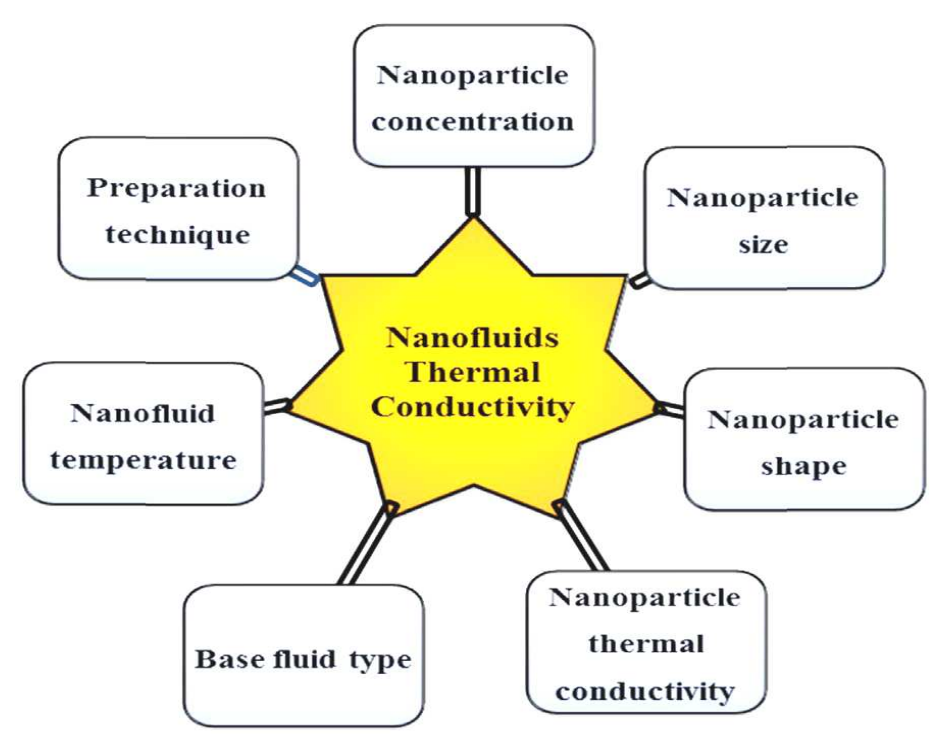

Figure 1: Factors Effecting Thermal Conductivity.

\section{Carbon Nanotubes}

Carbon Nanotubes (CNTs) are allotropes of carbon with a round and empty nanostructure. These tube shaped carbon molecules have uncommon properties, which are significant for nanotechnology, equipment and distinctive fields of materials science and advancement. Attributable to the materials outstanding quality and solidness, nanotubes have been created with length-to-breadth extent of up to 132,000,000:1, altogether bigger than for some other material by and large greater than for some other material. In addition, attributing to their exceptional thermal conductivity, mechanical, and electrical properties, carbon nanotubes find applications as added substances to various fundamental materials. Fig. 2 describes the methodology followed in investigation. Fig.3 indicates the experimental setup used for the present investigation.

\section{METHODOLGY}

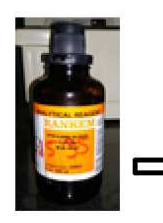

1

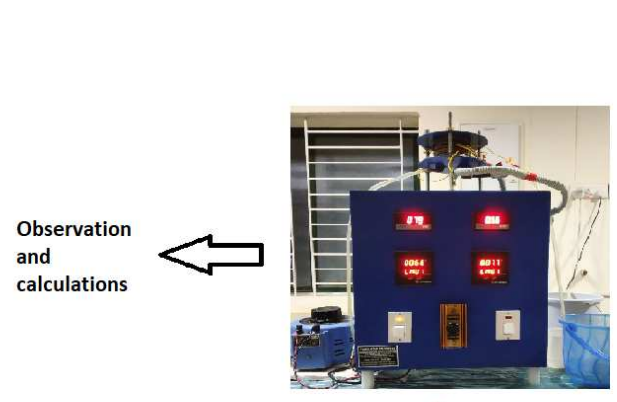

6

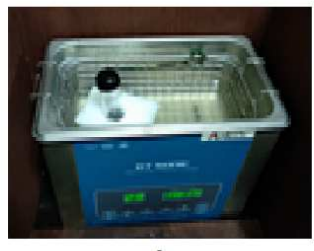

4

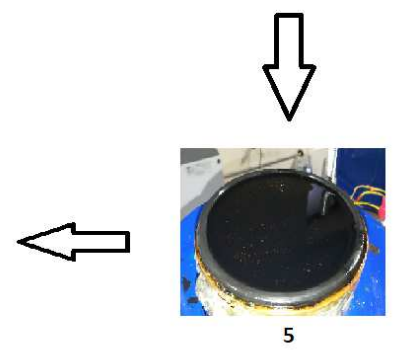

Figure 2: Methodology. 


\section{Process Involved}

- Ethylene glycol,

- $\quad$ MWCNT Powder

- $\quad$ MWCNT + Ethylene glycol

- Soniction

- $\quad$ PPTC Test section

- $\quad$ PPTC Apparatus

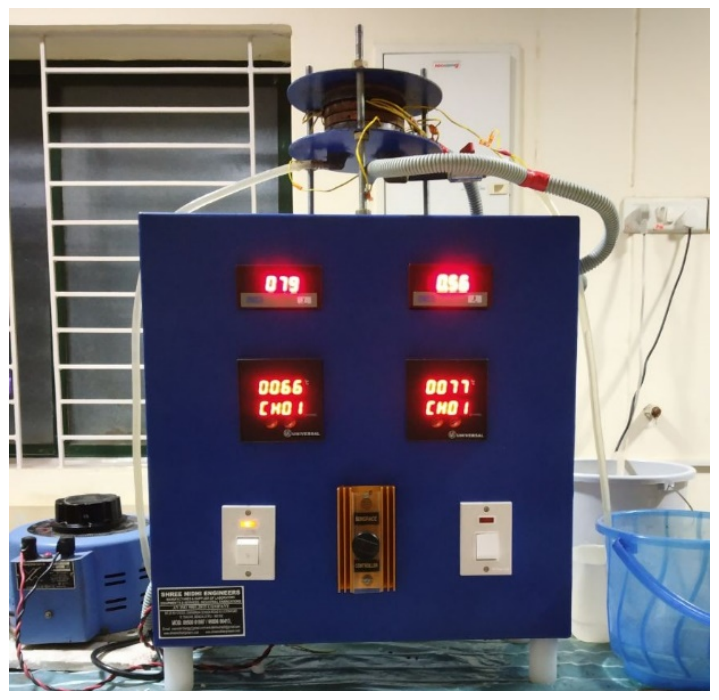

Figure 3: Experimental Setup.

\section{Steady State Parallel Plate Method}

The determination of the thermal conductivity with the parallel plate principle surely represents the method with the longest tradition. However, the long measuring time and insufficient measuring accuracy in spite of complex corrections are the main reasons for the fact that parallel plate instruments are hardly used as standard technology so far. Nevertheless, the method offers remarkable advantages such as the simple geometrical configuration. The planar form of the measuring volume allows measurements not only for fluids and bulk materials, but also for solid bodies. Exact adjustment and determination of the temperatures, the geometrical parameters of the measuring volume, the heating power for the heating plate allow absolute estimations of the thermal conductivity for many kinds of materials with $97 \%$ confidence and $3 \%$ error. 


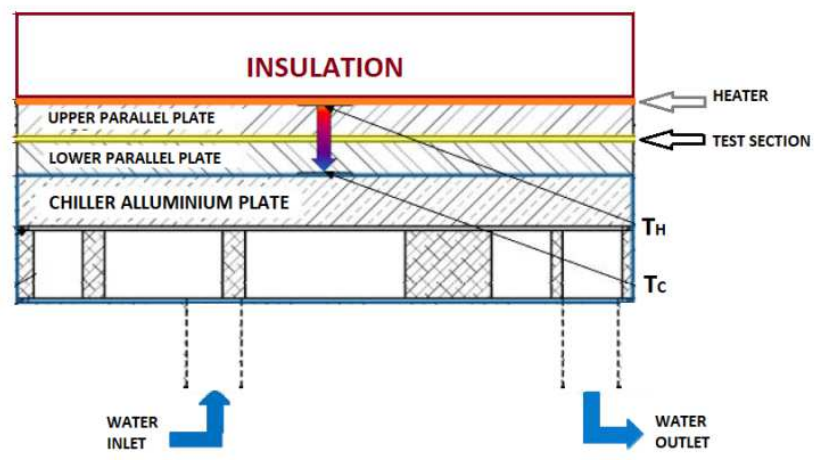

Figure 4: PPTC Design.

\section{Parallel-Plate Apparatus Design and Method}

The consistent-state parallel plate technique utilize basic heat transfer idea to gauge thermal conductivity of material sample by utilizing one dimensional heat conduction equation and idea of thermal resistance. The fluid example is set between upper copper plate and the lower copper plate. An O-ring is utilized to make a space between upper copper plate and the lower copper plate to fill in a fluid example. The heat flux streams toward the path from radiator to the lower copper plate.. After consistent temperature, contrast between the upper surface of upper copper plate and lower surface of lower copper plate is achieved; the thermal conductivity of material example can be determined from one-dimensional heat conduction equation. Any instrument to be designed needs specific software's, since we have used Autodesk inventor, CATIA, ANSYS fluent for simulation and designing instrument. While designing, the errors which were found in previous levels were tried to be eliminated, specifically improved experimental test section height and area. It is made flexible for removal of used solution (Nano fluids).

- The apparatus is altogether calibrated so as to ensure precise estimation results.

- The consistency and in general precision of PPTC device has been calibrated utilizing Ethylene glycol.

- The PPTC apparatus displays an error of about $3 \%$ with $97 \%$ confidence.

- Graph which depicts the calibration with ethylene glycol is given below.

Equations used for the analysis are described below

One-Dimensional Heat Conduction Equation

$$
k_{F}=\frac{L_{F}}{A \cdot\left(\frac{T_{H}-T_{C}}{Q_{x}}-\frac{2 L_{c u}}{k_{c u} A}\right)}
$$




\section{Predicted Models}

Hamilton and Crosser Model

$$
\frac{k_{\mathrm{eff}}}{k_{\mathrm{f}}}=\frac{k_{\mathrm{p}}+(n-1) k_{\mathrm{f}}-(n-1) \phi\left(k_{\mathrm{f}}-k_{\mathrm{p}}\right)}{k_{\mathrm{p}}+(n-1) k_{\mathrm{f}}+\phi\left(k_{\mathrm{f}}-k_{\mathrm{p}}\right)}
$$

Koo and kleinstreuer model

$$
\begin{aligned}
& \frac{k_{\text {static }}}{k_{f}}=\frac{k_{p}+2 k_{f}+2\left(k_{p}-k_{f}\right) \phi}{k_{p}+2 k_{f}-2\left(k_{p}-k_{f}\right) \phi} \\
& k_{\text {brownian }}=5 * 10^{4} * \beta \phi \rho_{f} c_{p f} \sqrt{\frac{k_{B} T}{\rho_{p} d_{p}}} f \\
& k_{n f}=k_{\text {static }}+k_{\text {brownian }}
\end{aligned}
$$

\section{RESULTS AND DISCUSSIONS}

The experiment was conducted at different heat inputs. Five reading are noted down at different concentrations i.e., $0.05 \%, 0.1 \%, 0.15 \%, 0.25 \%, 0.35 \%$ by varying voltage from $40 \mathrm{~V}$ to $80 \mathrm{~V}$.From readings obtained, the value of the thermal conductivity of nanofluid was found. The reading were tabulated in the Table.1.1 to 1.3.

Table 1: Observation

\begin{tabular}{|c|c|c|c|c|c|c|}
\hline \multicolumn{7}{|c|}{ Observation Table of Ethylene Glycol and 0.1wt \% MWCNT } \\
\hline S.No & $\begin{array}{c}\text { Voltage } \\
(\mathbf{V})\end{array}$ & $\begin{array}{c}\text { Current } \\
(\mathbf{A})\end{array}$ & $\begin{array}{c}\text { Avg. Temperature of the Fluid }\left({ }^{\circ} \mathbf{C}\right) \\
\mathbf{T}_{\mathbf{h}}\left({ }^{\circ} \mathbf{C}\right)\end{array}$ & $\mathbf{T}_{\mathbf{c}}\left({ }^{\circ} \mathbf{C}\right)$ & $\mathbf{K}(\mathbf{W} / \mathbf{m k})$ \\
\hline 1 & 40 & 0.24 & 34.58 & 36 & 31 & 0.427 \\
\hline 3 & 50 & 0.3 & 42 & 43 & 35 & 0.417 \\
\hline 4 & 60 & 0.4 & 49.58 & 52 & 40 & 0.445 \\
\hline 5 & 80 & 0.57 & 60.16 & 64 & 46 & 0.395 \\
\hline
\end{tabular}

Table 2: Observation

\begin{tabular}{|c|c|c|c|c|c|c|}
\hline \multicolumn{7}{|c|}{ Observation Table of Ethylene Glycol and 0.25wt\% MWCNT } \\
\hline S.No & $\begin{array}{c}\text { Voltage } \\
(\mathbf{V})\end{array}$ & $\begin{array}{c}\text { Current } \\
(\mathbf{A})\end{array}$ & $\begin{array}{c}\text { Avg. Temperature of the fluid }\left({ }^{\circ} \mathbf{C}\right) \\
\mathbf{T}_{\mathbf{h}}\left({ }^{\circ} \mathbf{C}\right)\end{array}$ & $\mathbf{T}_{\mathbf{c}}\left({ }^{\circ} \mathbf{C}\right)$ & $\mathbf{K}(\mathbf{W} / \mathbf{m k})$ \\
\hline 1 & 40 & .22 & 35.25 & 36 & 32 & .528 \\
\hline 2 & 50 & .32 & 43.91 & 45 & 37 & .480 \\
\hline 3 & 60 & .39 & 51.91 & 54 & 42 & .467 \\
\hline 4 & 70 & .48 & 65.41 & 68 & 48 & .401 \\
\hline 5 & 80 & .57 & 76.83 & 80 & 54 & .419 \\
\hline
\end{tabular}


Table 3: Observation

\begin{tabular}{|c|c|c|c|c|c|c|}
\hline \multicolumn{7}{|c|}{ Observation Table of Ethylene Glycol and 0.35wt\% MWCNT } \\
\hline S.No & $\begin{array}{c}\text { Voltage } \\
(\mathbf{V})\end{array}$ & $\begin{array}{c}\text { Current } \\
(\mathbf{A})\end{array}$ & $\begin{array}{c}\text { Avg. Temperature of the Fluid }\left({ }^{\circ} \mathbf{C}\right) \\
\text { Upper Surface Temp. } \\
\text { Of Copper Plate } \mathbf{T}_{\mathbf{h z}}\left({ }^{\circ} \mathbf{C}\right)\end{array}$ & $\mathbf{T}_{\mathbf{c}}\left({ }^{\circ} \mathbf{C}\right)$ & $\mathbf{K}^{(\mathbf{W} / \mathrm{Mk})}$ \\
\hline 1 & 40 & .23 & 36.5 & 36 & 30 & .340 \\
\hline 2 & 50 & .31 & 39.5 & 43 & 33 & .343 \\
\hline 3 & 60 & .39 & 47.25 & 53 & 36 & .304 \\
\hline 4 & 70 & .48 & 56.58 & 65 & 39 & .286 \\
\hline 5 & 80 & .56 & 68.58 & 80 & 43 & .267 \\
\hline
\end{tabular}

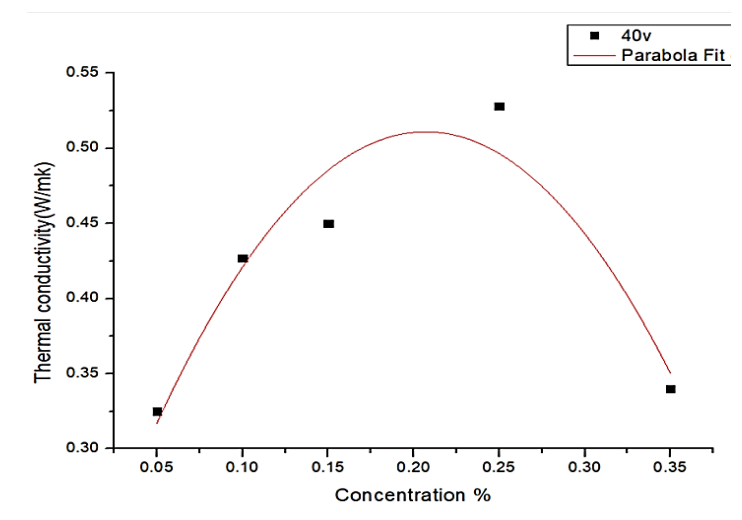

Figure 5: Thermal Conductivity Vs Concentration.

Fig. 5 shows the relation between thermal conductivity (K) Vs concentration (\%).Fig. shows upgrade in the thermal conductivity of nanofluids with various weight portions of the MWCNT. A significant increment in the thermal conductivity was found with the expansion in the MWCNT focus for nanofluid. As graph shows, thermal conductivity was found to be increased upto an optimum level of $0.25 \mathrm{wt} \%$ concentration, further it decreases with increasing concentration. The decrease in thermal conductivity was assumed due to Agglomeration of nano particles at higher concentration, which shows that optimum addition of nanoparticles to nanofluids gives better results of thermal conductivity in CNT- Ethylene glycol based nanofluids. An enhancement in thermal conductivity of $53.03 \%$ was observed at $\varphi=0.25 \%$. The large enhancement for CNT-based nanofluids is due to a very high thermal conductivity of carbon nanotubes compared to other nanoparticles reported in the studies just cited. There are four other conceivable clarifications for the odd increment of thermal conductivity, Brownian movement of the nanoparticles, atomic dimension layering of the fluid at the fluid/molecule interface, the nature of heat transport in the nanoparticles, and the impacts of nanoparticle grouping.

\section{CONCLUSIONS}

The present work concerns the measurement of thermal conductivity of ethylene glycol based MWCNT-Nanofluids with the help of PPTC apparatus. The PPTC apparatus designed was calibrated with Ethylene glycol and showed 3\%error with 97\% confidence. The tests are done to interpret the discrepancies between the deliberate \& predicted data. The thermal conductivity was found to be increased upto an optimum level of $0.25 \mathrm{wt} \%$ concentration. Further it decreases with increasing concentration. The decrease in thermal conductivity was assumed due to Agglomeration of nanoparticles at higher concentration. 


\section{REFERENCES}

1. Milivoje M. Kostic and Casey J.Walleck, Design of steady state PPTC apparatus for Nano fluids.

2. Yimin Xuan, Qiang Li, Investigation on convective heat transfer and flow features of nanofluids. International journal of heat and fluid flow 21(2000) 58-64

3. Amir Qashqaei \& Ramin Ghasemi Asl, "Numerical Modeling and Simulation of Copper Oxide nanofluids Used in Compact Heat Exchangers “, International Journal of Mechanical Engineering (IJME), Vol. 4, Issue 2, pp. 1-8

4. Xiang-Qi, Arun S Mujumdar, Heat transfer characteristics of nanofluids: a review international journal of thermal sciences 46(2007)1-19

5. Dongsheng Wen, yulong ding, experimental investigation into convective heat transfer of nanofluids at the entrance region under laminar flow conditions, International journal of heat and mass transfer 47 (2004) 5181-5188

6. Xinwei wang and Xianfan Xu, Thermal conductivity of Nanoparticle-Fluid mixture.

7. Meibo Xing, Jianlin Yu, Ruixiang Wang, Experimental study on the thermal conductivity enhancement of water based nanofluids using different types of carbon nanotubes, International Journal of Heat and Mass Transfer 88 (2015) 609-616.

8. R.L. Hamilton, O.K. Crosser, IEC Fundamentals 2 (1962) 187.

9. R. K. Dhal, "Vorticity on MHD Free Convection Flow of Fluid with Heat Transfer through Porous Medium by an Oscillating Porous Plate in Slip Flow Region”, BEST: International Journal of Humanities, Arts, Medicine and Sciences (BEST: IJHAMS), Vol. 3, Issue 7, pp. 77-82

10. Walleck, C.J., 2009, Development of Steady-State, Parallel-Plate Thermal Conductivity Apparatus for PolyNanofluids And Comparative Measurements with Transient HWTC Apparatus,M. S. Thesis, Northern Illinois University, DeKalb, IL.

11. M.S. Liu, M.C.-C. Lin, I.-T.E. Huang, C.-C. Wang, Enhancement of thermal conductivity with carbon nanotube for nanofluids, Int. Commun. Heat MassTransfer32 (9) (2005) 1202-1210

12. Das SK, Putra N, Thiesen P, Roetzel W. Temperature dependence of thermal conductivity enhancement for nanofluids. J Heat Transf 2003; 125:567-74.

13. V. Murali Krishna, "Heat Transfer Enhancement by using CuO-Water Nanofluid in a Concentric Tube Heat Exchanger-an Experimental Study”, International Journal of Mechanical Engineering (IJME), Vol. 6, Issue 1; pp.11-20

14. R.K. Shukla, V.K. Dhir, Effect of Brownian motion on thermal conductivity of nanofluids, J. Heat Transf. 130 (2008) 042406042412 
